\title{
ASSOCIATION BETWEEN EMOTIONAL-VOLITIONAL DYSFUNCTION AND FEATURES OF AGGRESSION OR HOSTILITY IN MENS WITH DIFFERENT FORMS OF SUBSTANCE ADDICTIONS: A CROSS-SECTIONAL STUDY
}

D0I: 10.36740/WLek202006109

\author{
Liliia V. Zhyvotovska', Dmytro I. Boiko ${ }^{1}$, Nataliia V. Kadzhaia ${ }^{2}$, Anastasia D. Shkodina', Iryna V. Demianenko ${ }^{1}$, \\ Volodymyr V. Borysenko' \\ ${ }^{1}$ UKRAINIAN MEDICAL STOMATOLOGICAL ACADEMY, POLTAVA, UKRAINE \\ 2POLTAVA REGIONAL NARCOLOGICAL DISPENSARY, POLTAVA, UKRAINE
}

\begin{abstract}
The aim: The research aim was to study features of emotional-volitional sphere and its association in mens with different forms of Substance Addictions.

Materials and methods: We examined 146 patients with alcohol and drug addictions using Toronto Alexithymia Scale, Zverkov-Eidmann`s questionnaire and Buss-Durkee questionnaire.

Results: The study showed an increase in the overall level of alexithymia, a moderate level of aggressiveness and a sufficient level of volitional self-regulation without a significant difference between the groups. The indirect correlation of "persistence" with the "general level of alexithymia", "difficulty identifying feelings" and "physical aggression" in group 1 and at the same time the indirect correlation between "self-control"and "verbal aggression" and "volitional self-regulation" with "difficulty describing feelings" can be explained by the opposite meaning of these concepts and phenomena themselves.However, it is interesting that the indicators "physical aggression" and "difficulty describing feelings" in group 2 were significantly lower, but at the same time correlated with "general level of alexithymia" and "irritability", respectively. On other hand in group 1 the indicator "suspiciousness" is directly related to the "general level of alexithymia", but its level is significantly lower in comparison with group 2.

Conclusions: The phenomenon of alexithymia is not only recorded in the clinical picture of patients with various forms of addiction, but can also induce the development of manifestations of aggressiveness and hostility in them. Correction of alexithymia is necessary to understand the emotional state of these patients and choose the right approach to their treatment and rehabilitation.
\end{abstract}

KEY WORDS: alexithymia, hostility, aggression, volitional regulation, substance addiction

Wiad Lek. 2020;73(6):1129-1133

\section{INTRODUCTION}

Addiction remains a significant public health concern. The problem of alcohol and drug addictions in according to its significant social role has important subject either for psychiatrists and narcologists or for other physicians. Now the most accepted point of view is supposed biopsychosocial approach considering alcohol addiction as a result of complex interaction of biological, psychological and social factors [1].

Alexithymia refers to the difficulty in identifying and describing feelings, the inability to discriminate between feelings and physical sensations, having a limited fantasy life and the inclination to an externally oriented way of thinking [2]. Alexithymia, which results in poor emotional regulation and stress-management abilities, has sometimes been considered as a vulnerability factor for medical and psychiatric illnesses. Alexithymia has been described as having five main components: a difficulty in identifying one's emotions, a difficulty in describing self-feelings verbally, a reduction or incapability to experience emotions, an externally orientated cognitive style and poor capacity for fantasising or symbolic thought [3].
Alexithymia rates in the general population have been reported to be $9 \%$ to $17 \%$ for men and $5 \%$ to $10 \%$ for women, whereas estimates are as high as $70 \%$ in some clinical groups [4]. Some researches shown that people with substance abuse disorder have more problems in alexithymia in comparison to the normal people $[5,6]$. Alexithymia is a multifaceted construct that has a complex relationship with various risk factors and psychological drinking constructs [7].

If the context of addiction is saturated with emotions, then reality, on the contrary, becomes emotionally impoverished, in real social relations the intensity of the emotional background decreases. This is especially noticeable when the attitude of others to the addict changes in a negative way. His detachment begins to perform a defensive reaction [8].

Personal self-regulation is a control of different mental activities and managing in an adequate and identified way. Self-regulation is a leading process of a personal psychological and physiological state [9]. Nowadays there is still inconsistent evidence about the role of self-regulation in 
addiction's development. There is data which indicate lower rates of self-regulation in patients with Substance Abuse Disorder than non-clinical samples, but no significant associations were found between self-regulation with addiction severity [10]. However numerous behavioral treatments for addictive disorders include components explicitly aimed at targeting self-regulation (e.g., coping and emotion regulation) [11]

Aggressive and hostility are one of the typical features of addictive behavior. It is known that addicts who had higher scores on aggression and hostility reported more situations that triggered their use of substances and less confidence that they could resist using when faced with such situations in the future. This was especially true for situations involving unpleasant internal states, situations involving rejection, and situations involving conflict with family and friends [12]. In these patients aggressiveness and hostility usually develop in the absence or restriction of the use of psychoactive substances, but their features depending on emotional and will disorder remain poorly understood.

\section{THE AIM}

The research aim was study emotional-volitional dysfunction and its association with features of aggression and hostility in mens with substance addiction.

\section{MATERIALS AND METHODS}

\section{STUDY DESIGN}

Institution based observational cross-sectional study design was employed.

\section{SETTINGS}

The study was conducted in Poltava Regional Drug Addiction Dispensary (Poltava, Ukraine) from September, 5 - February, 20, 2019.

\section{PARTICIPANTS}

We examined 146 men of the age of 24 to 52 years old who were treated at the detoxication therapy stage. The eligibility criteria were voluntary informed consent to participate in the study; male; age over 18; clinical diagnosis: «Mental and behavioural disorders due to use of alcohol. Dependence syndrome. Currently abstinent but in a protected environment» (F10.21), «Mental and behavioural disorders due to multiple drug use and use of other psychoactive substances. Dependence syndrome. Currently abstinent but in a protected environment» (F19.21). Exclusion criteria were female sex, age younger than 18 years, concomitant severe somatic pathology. We declare that during the study of patients' rights, they have been taken into account in accordance with the requirements of the Helsinki Convention. Patients were divided into two experimental groups, namely, group 1 which consisted of 81 mens with a clinical diagnosis of F19.21, and group 2 included 65 mens with a diagnosis of F10.21.

\section{VARIABLES}

We studied severity of Alexithymia, Volitional Self-regulation and Manifestations of aggressiveness and hostility. As potential confounders we described age and duration in hospital before examination.

\section{MEASUREMENTS}

The level of severity of alexithymia was studied according to the Russian version of the Toronto Alexithymia Scale (TAS-20R,) which was validated in 2010. It comprises three main factors. Difficulty identifying feelings (DIF) assesses a person's ability to recognise their emotions, difficulty describing feelings (DDF) assesses a person's ability to communicate their emotions to others, and externally oriented thinking (EOT) assesses a person's tendency to focus their attention externally [13].

Volitional self-regulation was evaluated for the Zverkov-Eidmann's questionnaire. It includes three scales: the definition of the generalized level of volitional self-regulation (VSR) which described the ability to consciously manage their own actions, emotions and states, the subclass - the "Persistence" $(\mathrm{P})$ which characterizes the available potential conscious mobilization of the completion of action, and the subclass - "self-control" (SC) which accord to the level of arbitrary emotional control reactions and states [14].

Manifestations of aggressiveness and hostility were assesed by the Buss-Durkee questionnaire with the calculation 8 subscales, namely physical aggression (PA), indirect aggression (IA), irritability (Ir), negativism (N), insult (I), suspicion (S), verbal aggression (VA), feelings of guilt (FG), and indices of aggression (IndA) and hostility (IndH) [15].

\section{STUDY SIZE}

Study size was arrived at GPower 3.1.9.4, using d-Coen `s effect size -0.417 (by pilot study), $\alpha=0.05$ and power was $80 \%$ [16]. As a result, final sample size was 81 patients in first group and 65 in the second one.

\section{STATISTICAL METHODS}

The obtained data was subjected to statistical processing. Medians (Me) and interquartile interval (IQR) or mean (M) and standart deviation (SD) were calculated for each variation line. We apply the criteria of Shapiro-Wilk for evaluate the normality of distribution. If data was normal distributed, we have used parametric Students test for two independent groups. Nonparametric methods were used for statistical analysis - U-test of Mann-Whitney (for two independent groups) and Spearmen linear correlation coefficient since the distribution was non-normal. Statistical 


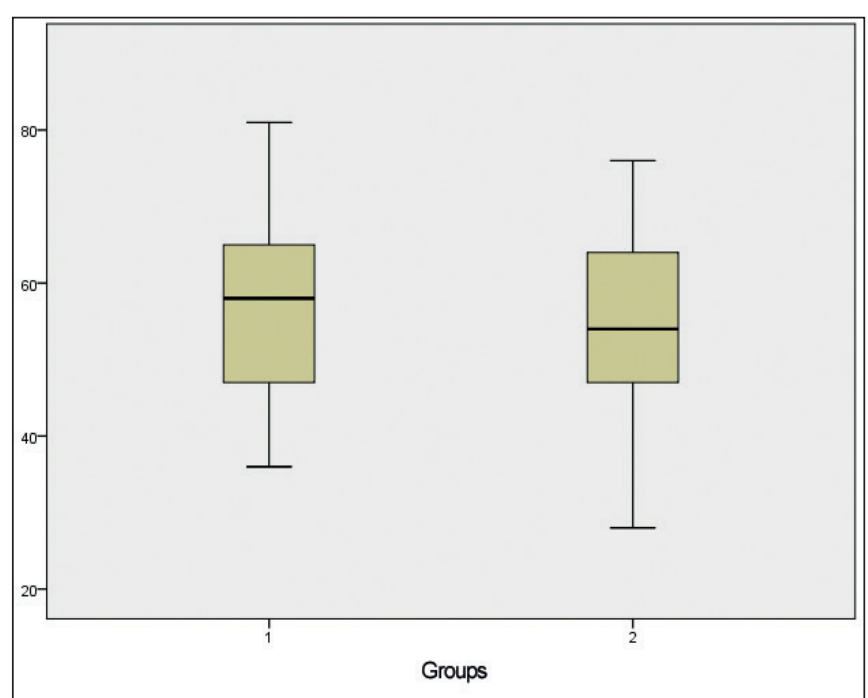

Fig. 1. Overall level of Alexithymia by TAS-20R in groups.

calculations were performed using the IBM SPSS Statistics 23.0. The results were considered statistically significant at $\mathrm{p} \leq 0,05$.

\section{RESULTS}

Average age in the group 1 was $36.3 \pm 7.1$ years, and in $2-38.9 \pm 12.5$ years.

Duration in hospital before examination was 14 days in each group.

The investigate of the alexithymia revealed that its overall level in the second group was not significantly differ from ones in the first, although the score in both groups remained within an elevated level, namely in the first group - 58.0 (47.0-62.25), in the second - 54.0 (47.0-64.5) which demonstrated on fig 1.

Level of DIF was 21.9 \pm 3.9 in the first and 21.6 \pm 6.5 in the second group, at the same time level of EOT was $18.7 \pm 6.2$ and 19.1 \pm 4.4 accordingly, but both are not differ significant. The total score of DDF in patients of group 1 was $16.4 \pm 3.9$ and in ones of group 2 was $14.3 \pm 4$.1. It is significantly higher by $14.7 \%$ compared to group 2, which showed on fig. 2 .

There were no statistical differences in the indicators that describes volitional self-regulation. The results indicating a sufficient level were within average values, namely rating of VSR in group $1-12.3 \pm 4.5$ and in group $2-12.1 \pm 4.5$, SC $-8.1 \pm 3.5$ and $8.6 \pm 3.3$ accordingly and $P-6.6 \pm 2.7$ in first and 6.2 \pm 2.6 in second groups. It was presented on fig.3.

Analysis of subscale by the Buss-Durkee questionnaire demonstrated next values in group 1 and 2 respectively: $\mathrm{PA}-5.9 \pm 1.6$ and $5.2 \pm 1.9, \mathrm{IA}-5.2 \pm 1.4$ and $5.3 \pm 2.1, \mathrm{Ir}-5.9 \pm 2.1$ and $6 \pm 2.3, \mathrm{~N}-3.2 \pm 1.6$ and $3.6 \pm 1.3, \mathrm{I}-5.1 \pm 1.6$ and $5.8 \pm 1.2$, $\mathrm{S}-6.3 \pm 1.9$ and $7.9 \pm 1.9, \mathrm{VA}-7.9 \pm 2.3$ and $7.6 \pm 1.8, \mathrm{FG}-7.4 \pm 1.2$ and 7.8 \pm 1.3 . It was discovered that the $\mathrm{S}, \mathrm{I}$ and $\mathrm{FG}$ indices were significantly higher by $25.4 \%, 13.7 \%$ and $5.1 \%$ respectively in the second group, while the PA was higher by $13.5 \%$ in the first group compared to the second, which showed on fig.4.

The IndA of both groups was within the average values and have not significant difference, namely in group

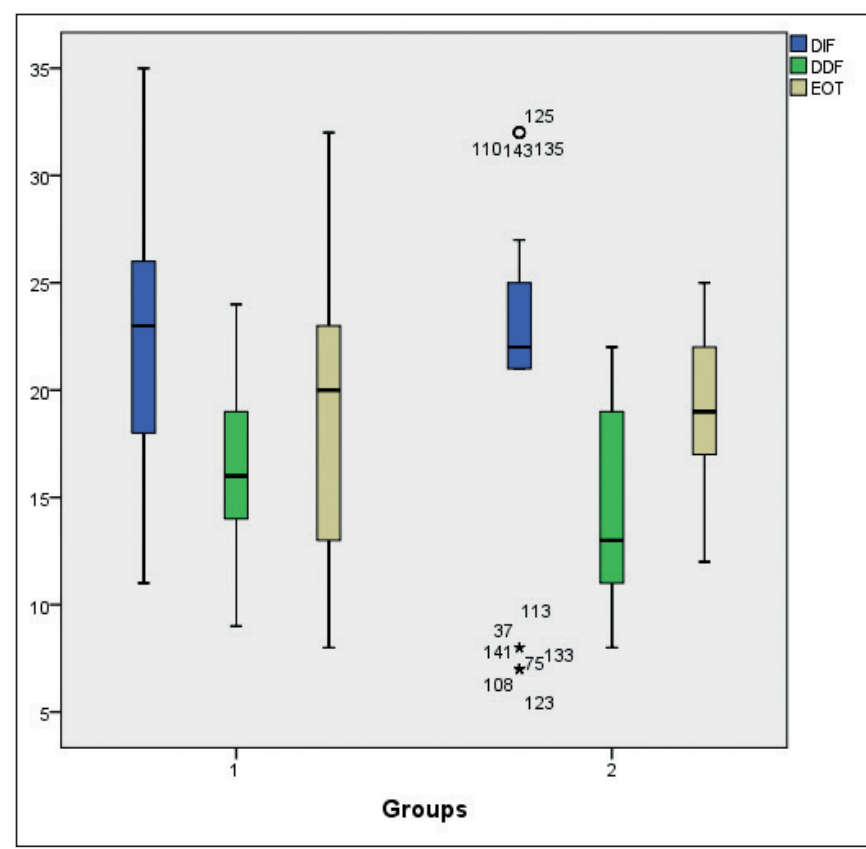

Fig. 2. Features of subscales by TAS-20R in groups.

$1-19.7 \pm 3.5$ and in group $2-19.1 \pm 5.3$. Ind $H$ in patients from group 2 was defined higher by $17.5 \%$ compared with group 1, although the performance of both groups was above the upper limit of normal values. It was presented on fig. 5 .

A detailed analysis of the indicators of patients in the first group revealed a direct moderate correlation between alexithymia and $\operatorname{Ir}\left(\mathrm{r}_{1}=0,311, \mathrm{p}_{1}=0,025\right)$, DIF and $\mathrm{S}$ $\left(r_{1}=0,332, p_{1}=0,016\right)$; indirect moderate correlation between VSR and PA $\left(r_{1}=-0,515, p_{1}=0,006\right), I\left(r_{1}=-0,341\right.$, $\left.\mathrm{p}_{1}=0,013\right)$, between $\mathrm{P}$ and PA $\left(\mathrm{r}_{1}=-0,504, \mathrm{p}_{1}=0,002\right)$, DIF $\left(r_{1}=-0,358, p_{1}=0,009\right)$, level of alexithymia $\left(r_{1}=-0,352\right.$, $\left.\mathrm{p}_{1}=0,010\right)$, between SC and $\mathrm{I}\left(\mathrm{r}_{1}=-0,392, \mathrm{p}_{1}=0,004\right)$, $\mathrm{S}\left(\mathrm{r}_{1}=-0,490, \mathrm{p}_{1}=0,003\right)$; and indirect small correlation between SC and PA $\left(r_{1}=-0,274, p_{1}=0,049\right)$.

In the second group there were defined direct moderate correlation between DDF and $\operatorname{Ir}\left(r_{2}=0,561, p_{2}=0,007\right)$, and between alexithymia and PA $\left(\mathrm{r}_{2}=0,548, \mathrm{p}_{2}=0,008\right)$, $\mathrm{N}\left(\mathrm{r}_{2}=0,543, \mathrm{p}_{2}=0,009\right)$; indirect strong correlation between SC and VA $\left(r_{2}=-0,731, p_{2}=0,002\right)$, between VSR and DDF $\left(r_{2}=-0,713, p_{2}=0,008\right)$; indirect moderate ones between VSR and VA $\left(r_{2}=-0,573, p_{2}=0,005\right)$, between SC and FG $\left(r_{2}=-0,436, p_{2}=0,043\right), \operatorname{DDF}\left(r_{2}=-0,667\right.$, $\left.\mathrm{p}_{2}=0,003\right)$, between $\mathrm{P}$ and DDF $\left(\mathrm{r}_{2}=-0,632, \mathrm{p}_{2}=0,004\right)$, between EOT and VA $\left(r_{2}=-0,471, p_{2}=0,027\right)$.

We determine correlation in the both groups between follow indicators: indirect moderate between IA and VSR $\left(r_{1}=-0,609, p_{1}=0,017 ; r_{2}=-0,515, p_{2}=0,014\right), P\left(r_{1}=-0,470\right.$, $\left.\mathrm{p}_{1}=0,007 ; \mathrm{r}_{2}=-0,540, \mathrm{p}_{2}=0,010\right), \mathrm{SC}\left(\mathrm{r}_{1}=-0,510\right.$, $\left.\mathrm{p}_{1}=0,003 ; \mathrm{r}_{2}=-0,560, \mathrm{p}_{2}=0,007\right)$ and FG with $\mathrm{P}$ $\left(r_{1}=-0,320, p_{1}=0,017 ; r_{2}=-0,453, p_{2}=0,034\right)$; between Ir and VSR, $\mathrm{P}$ and SC indirect moderate in the first group $\left(r_{1}=-0,425, p_{1}=0,002 ; r_{1}=-0,324, p_{1}=0,019 ; r_{1}=-0,510\right.$, $\left.\mathrm{p}_{1}=0,017\right)$ and indirect strong in the second one $\left(\mathrm{r}_{2}=-0,711\right.$, 


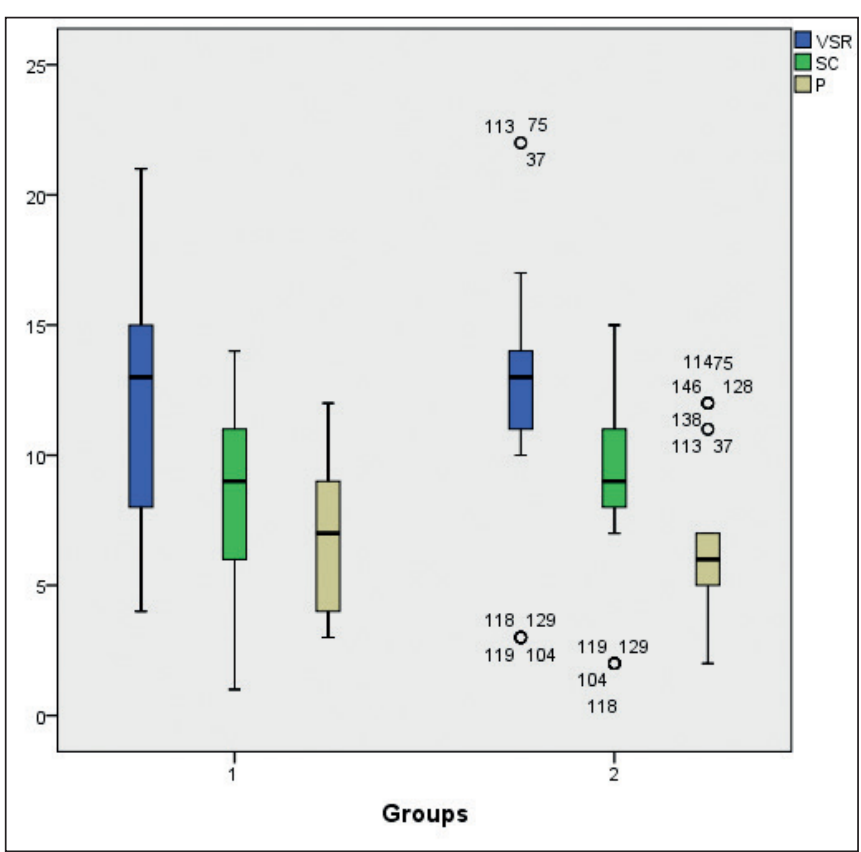

Fig.3. Rating of volitional self-regulation by theZverkov-Eidmann`squestionnaire.

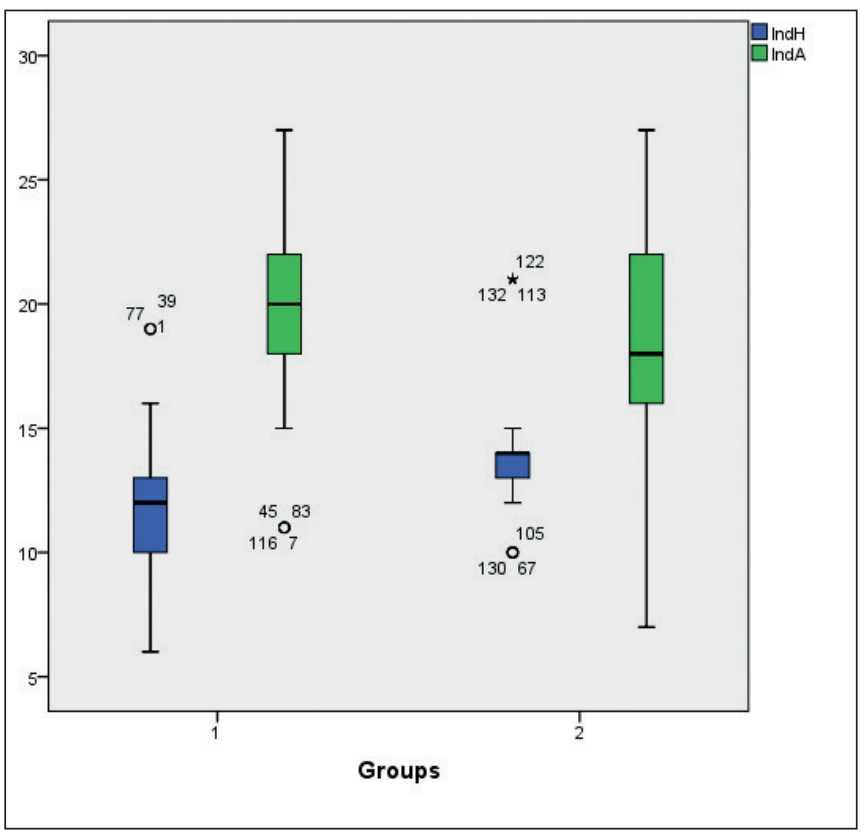

Fig. 5. Evaluating of indices by the Buss-Durkee questionnaire.

$\left.\mathrm{p}_{2}=0,004 ; \mathrm{r}_{2}=-0,713, \mathrm{p}_{2}=0,005 \mathrm{r}_{2}=-0,720, \mathrm{p}_{2}=0,007\right)$ in accordance; between $\mathrm{P}$ and VA direct moderate in the first group $\left(r_{1}=0,420, p_{1}=0,002\right)$ and indirect strong in the second group $\left(r_{2}=-0,724, p_{2}=0,016\right)$.

\section{DISCUSSION}

The study showed an increase in the overall level of alexithymia, a moderate level of aggressiveness and a sufficient level of volitional self-regulation without a significant difference between the groups. The indirect correlation of "persistence" with the "general level of alexithymia",

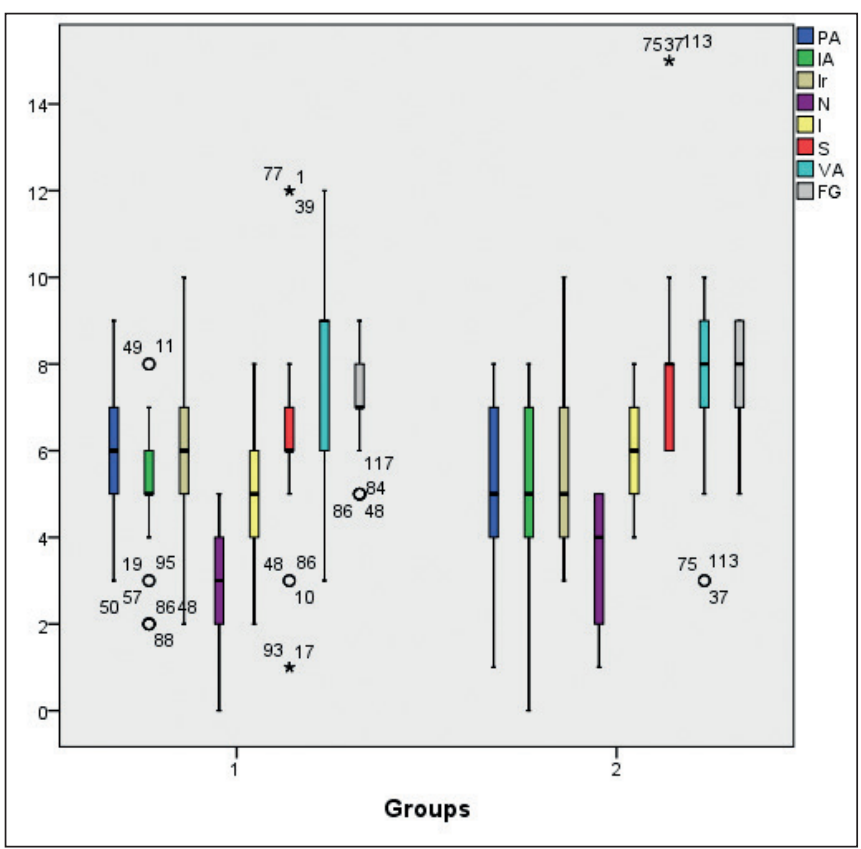

Fig. 4. Rating of subscales by the Buss-Durkee questionnaire.

"difficulty identifying feelings" and "physical aggression" in group 1 and at the same time the indirect correlation between "self-control" and "verbal aggression" and "volitional self-regulation" with "difficulty describing feelings" can be explained by the opposite meaning of these concepts and phenomena themselves.

However, it is interesting that the indicators "physical aggression" and "difficulty describing feelings" in group 2 were significantly lower, but at the same time correlated with "general level of alexithymia" and "irritability", respectively. On other hand in group 1 the indicator "suspiciousness" is directly related to the "general level of alexithymia", but its level is significantly lower in comparison with group 2 .

It can be assumed that the described manifestations of aggressiveness and hostility were secondary and arose due to the inability of patients to identify their true experiences. As a result, these secondary emotional manifestations, arising as a response to alexithymia, and not to the underlying disease, distort the clinical picture, while primary emotions may remain unidentified by the patient and not detected during therapy. With a superficial examination, this can lead to the fact that some of the "targets" of therapy will remain without impact, which, in turn, may affect the quality of treatment and the stability of remission.

On the other hand, one should not confuse the difficulty of identifying certain feelings with a reluctance to recognize these symptoms. Psychotherapeutic measures aimed at manifestations not identified by the patient himself can lead to a decrease in compliance with the therapist. Therefore, we consider it necessary to initially carry out the correction of alexithymia, along with the treatment of the underlying disease, with the subsequent impact on the already identified and conscious manifestations of hostility and aggressiveness. 


\section{CONCLUSIONS}

The phenomenon of alexithymia is not only recorded in the clinical picture of patients with various forms of addiction, but can also induce the development of manifestations of aggressiveness and hostility in them. Correction of alexithymia is necessary to understand the emotional state of these patients and choose the right approach to their treatment and rehabilitation.

Further studies of alexithymia in patients with different forms of addiction will improve understanding of this phenomenon and modernize existing treatment and rehabilitation programs.

\section{REFERENCES}

1. Zhyvotovska L.V., Borysenko V.V., Scrypnikov A.M. Osobystisni osoblyvosti patsiientiv iz zapiinymy formamy alkoholnoi zalezhnosti [Personal features of patients with dipsomaniac forms of alcohol addiction]. Medychna psykholohiia. 2017;3:67-70. (in Ukrainian).

2. Haan H., Joosten E., Wijdeveld T. et al. Alexithymia is not a stable personality trait in patients with substance use disorders. Psychiatry Research. 2012;198(1):123-9. doi: 10.1016/j.psychres.2011.09.027

3. Hemming L., Taylor P., Haddock G. et al. A systematic review and metaanalysis of the association between alexithymia and suicide ideation and behavior. Journal of Affective Disorders. 2019; 254:34-48. doi: 10.1016/j. jad.2019.05.013

4. Mattila A.K., Ahola K., Honkonen T. et al. Alexithymia and occupational burnout are strongly associated in working population. Journal of Psychosomatic Research. 2007;62:657-65. doi: 10.1016/j. jpsychores.2007.01.002

5. Ghorbani F., Khosravani V., Bastan V.S. et al. The alexithymia, emotion regulation, emotion regulation difficulties, positive and negative affects, and suicidal risk in alcohol-dependent outpatients. Psychiatry Research. 2017;252:223-30. doi: 10.1016/j.psychres.2017.03.005.

6. Hamidi S., Rostami R., Farhoodi F. et al. A study and comparison of Alexithymia among patients with substance use disorder and normal people. Procedia - Social and Behavioral Sciences. 2010;5:1367-70. doi: 10.1016/j.sbspro.2010.07.289

7. Cruise K.E., Becerra R. Alexithymia and problematic alcohol use: A critical update. Addict Behav. 2018 Feb;77:232-46.

8. Skrypnikov A.M., Zhyvotovska L.V., Herasymenko L.O. et al. Alexithymia in healthy people and its role in development of different disorders. The Medical and Ecological Problems. 2019;23(1-2):30-3. doi: 10.31718/ mep.2019.23.1-2.07

9. Berdibayeva S., Nurdaulet I., Saparbaikyzy S. et al. Psychological Features of Gender Relations in Self-regulation of Personality. Procedia - Social and Behavioral Sciences. 2015;171:203-8. doi: 10.1016/j. sbspro.2015.01.108.

10. Ghalehban M., Besharat M.A. Examination and Comparison of Alexithymia and Self-Regulation in Patients with Substance Abuse Disorder and Normal Individuals. Procedia - Social and Behavioral Sciences. 2011;30:38-42. doi: 10.1016/j.sbspro.2011.10.008

11. Roos C.R., Witkiewitz K. A contextual model of self-regulation change mechanisms among individuals with addictive disorders. Clinical Psychology Review. 2017;57:117-28. doi: 10.1016/j.cpr.2017.08.008
12. McCormick R.A.,Smith M. Aggression and hostility in substance abusers: The relationship to abuse patterns, coping style, and relapse triggers. Addict Behav. 1995:20(5):555-62.

13. Taylor G.J., Kvilty L.K., Bagbi M. et al. Nadezhnost i faktorialnaya validnost russkoy versii 20-punktovoy torontskoy shkalyi aleksitimii [Reliability and factorial validity of the russian version of the 20 -item Toronto alexithymia scale]. Sotsialnaya i klinicheskaya psihiatriya. 2012;22(3):20-25. (in Russian).

14. Chudakova V.P. Doslidzhennia «volovoho samokontroliu/volovoi samorehuliatsii» - pokaznyka sformovanosti psykholohichnoi hotovnosti do innovatsiinoi diialnosti y konkurentozdatnosti osobystosti: diahnostychno-interpretatsiinyi component [The study of «volitional self-control / volitional self-regulation"- indicator of formation psychological readiness for innovation activity and competitiveness of the individual: diagnostic and interpretation component]. Osvita ta rozvytok obdarovanoi osobystosti. 2016 Jan;44(1):39-47. (in Ukrainian)

15. Greben N.F. Psihologicheskie testyi dlya professionalov. Minsk: Sovrem. Shk.; 2007. 496 p. (in Russian)

16. Faul F., Erdfelder E., Lang A.G. et al. G*Power 3: A flexible statistical power analysis program for the social, behavioral, and biomedical sciences. Behavior Research Methods. 2007;39:175-191.

The article is a fragment of the research "Clinical and psychopathological research and optimization of medical and rehabilitation-preventive measures in the conditions of various mental disorders with considering heliometeofactors and biological rhythms» (State registration number 0115U000839).

\section{ORCID and contributorship:}

Liliia V. Zhyvotovska - 0000-0002-1469-060X ${ }^{A, F}$

Dmytro I. Boiko - 0000-0001-7336-0822 A,C,D,F

Nataliia V. Kadzhaia - ${ }^{B}$

Anastasiia D. Shkodina - 0000-0002-7198-5498 C,D

Iryna V. Demianenko - 0000-0001-5485-5811 B,E

Volodymyr V. Borysenko - 0000-0002-2567-2044 ${ }^{E}$

\section{Conflict of interest:}

The Authors declare no conflict of interest.

\section{CORRESPONDING AUTHOR Dmytro I. Boiko}

Ukrainian Medical Stomatological Academy

23 Shevchenko St., 36000 Poltava, Ukraine

tel: +380500143648 ,

e-mail:bojk0998@gmail.com

Received: 01.03 .2020

Accepted: 08.05 .2020 